\title{
DOE/MT/92017--03
}

\section{Simultaneous $\mathrm{S0}_{2} / \mathrm{NO}_{x}$ Abatement Using Zeolite-Supported Copper}

\author{
Progress Report \\ October 1 - December 31, 1995
}

\author{
By: \\ Mark B. Mitchell \\ Mark G. White
}

Work Performed Under Contract No.: DE-FG22-92MT92017

For

U.S. Department of Energy Office of Fossil Energy Federal Energy Technology Center P.O. Box 880

Morgantown, West Virginia 26507-0880

By

Clark Atlanta University 223 James P. Brawley Drive Atlanta, Georgia 30314

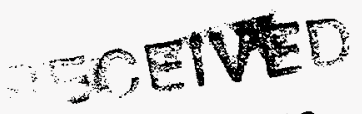

AUG 101998

OSTI 


\section{Disclaimer}

This report was prepared as an account of work sponsored by an agency of the United States Government. Neither the United State Government nor any agency thereof, nor any of their employees, makes any warranty, express or implied, or assumes any legal liabilit or responsibility for the accuracy, completeness, or usefulness of an information, apparatus, product, or process disclosed, or represents that its use would not infringe privately owned rights. Reference herein to any specific commercial product, process, or service by trade name, trademark, manufacturer, or otherwise does not necessarily constitute or imply its endorsement, recommendation, or favoring by the United States Government or any agency thereof. The views and opinions of authors expressed herein do not necessarily state or reflec those of the United States Government or any agency thereof. 


\section{DISCLAIMER}

Portions of this document may be illegible in electronic image products. Images are produced from the best available original document. 


\section{Abstract.}

Electron paramagnetic resonance (EPR) spectroscopy has been used to investigate the nature of copper ions supported on oxides and on zeolites. The results show that, unfortunately, EPR may not be a very useful predictor of the catalytic activity of supported copper catalysts.

\section{Introduction.}

Copper-impregnated catalysts, prepared using non-aqueous impregnation techniques as described earlier, were examined by electron paramagnetic resonance (EPR) in an attempt to determine the nature of the $\mathrm{Cu}^{2+}$ species in the samples. The samples are described as follows:

$\underline{\text { Sample ID }}$
$\mathrm{Cu}$ (bipy)dimer/SiO2
$\mathrm{Cu}$ (bipy)dimer $/ \mathrm{Z}-\mathrm{Y}$
$\mathrm{Cu}($ en) $2 / \mathrm{Z}-5$
$\mathrm{Cu}($ en) $2 \mathrm{Cl} 04$
$\mathrm{Cu}($ acetate $) / \mathrm{Z}-5$

Sample ID

(acetate)/Z-s
Metal Complex

copper bipyridil dimer

copper bipyridil dimer

copper ethylene diamine

copper ethylene diamine

copper acetate

\author{
Support \\ silica \\ zeolite $Y$ \\ zeolite ZSM-5 \\ none
}

zeolite ZSM-5

The copper loadings in these samples are similar for the supported samples $(1-2 \mathrm{wt} \% \mathrm{Cu})$. The raw data are shown in the attached figures. The data were collected at Emory University in the Department of Physics by a post-doctoral fellow under the supervision of Professor Hyn. Figure 1 is the EPR spectrum of unsupported copper ethylenediamine (as the perchlorate salt), and Figure 2 is the EPR spectrum of the same complex after impregnation in ZSM-5. The EPR spectra of copper bipyridil dimer on silica and inside $Y$ zeolite are shown in Figures 3 and 4. The EPR spectrum of the catalyst made according to the method of $\mathrm{Li}$ and Hall, copper acetate/ZSM-5, is shown in Figure 5.

The raw data was converted into calculated values of the perpendicular $\left(\mathrm{g}_{\perp}\right)$ and parallel $\left(g_{1}, A_{l}\right)$ components of the g-tensor and the hyperfine splitting tensor (A) using standard methods. These calculated constants are the fundamental molecular parameters which determine the EPR spectrum, and the tabulated values allow the easy comparison of the current work with 
that of others. The results of our earlier work for copper acetylacetonate and the literature data are also shown in Table 1.

Table 1. Observed g-tensor Values and Hyperfine Splitting Constants.

$\begin{array}{cccc}\text { Sample ID } & \mathrm{g}_{\perp} & \mathrm{g}_{\mathrm{I}} & \underline{\mathrm{A}}_{I_{2} \mathrm{~cm}^{-1}} \\ \mathrm{Cu}(\mathrm{en}) 2 \mathrm{C} 104 & 2.049 & 2.18 & 0.0108 \\ \mathrm{Cu}(\mathrm{en}) 2 / \mathrm{Z}-5 & 2.073 & 2.21 & 0.0192 \\ \mathrm{Cu}(\text { bipy)dimer/SiO2 (Rao) } & 2.076 & 2.29 & 0.0167 \\ \mathrm{Cu}(\text { bipy)dimer/SiO2 (Choksi) } & 2.09 & 2.34 & 0.0184 \\ \mathrm{Cu}(\text { bipy)dimer/Z-Y } & 2.095 & 2.30 & 0.0157 \\ \mathrm{Cu}(\text { acetate)/Z-5 } & 2.102 & & \\ \mathrm{Cu}(\text { acac)/silica } & 2.06 & 2.26 & 0.0200 \\ \mathrm{Cu} / \mathrm{Y} \text { zeolite } & 2.06 & 2.39 & 0.0134\end{array}$

Also included in Table 1 is previous data for isolated copper acetylacetonate/silica $(0.2 \mathrm{wt} \% \mathrm{Cu})$. These data are similar to the EPR data for $\mathrm{Cu}(\mathrm{en}) 2 / \mathrm{Z}-5$. We also show a comparison of the EPR data for the copper bipyridil dimer on silica and in $\mathrm{Y}$ zeolite. The literature values for copper bipyridil/silica are similar, however the literature for $\mathrm{Cu}$ ions in zeolite $\mathrm{Y}$, the EPR parameters are quite different for the data for the parallel component.

\section{Discussion.}

The $\mathrm{Cu}^{2+}$ ion in a square planar complex exhibits an "axial field" which means that the interaction of the unpaired electron with an external magnetic field is different in one direction (e.g. parallel to the axial direction) than in the perpendicular direction. The isolated complex exhibits two values of the g-vector. When hyperfine splitting is taken into account, a total of eight resonances can be predicted: four resonances each for the parallel and perpendicular directions. Often, the four resonances for the hyperfine splitting of the perpendicular vector are not well-resolved for spectra recorded at room temperature (such as the data presented here). Thus, the literature data report the g-values and the hyperfine splitting of the parallel component. 
From a consideration of Figures $I$ and 2, it is clear that the complex on the support shows a different EPR spectrum than that of the unsupported metal complex. These differences are summarized in the g-tensor data for which the $g_{\perp}$ and $g_{1}$ are different, as are the hyperfine splitting constants, $A_{1}$. The results for the ethylene diamine complex on silica resemble the earlier data reported for another metal complex on silica: copper acetylacetonate. Figures 3 and 4 for the copper bipyridil dimer on silica and in $\mathrm{Y}$ are not significantly different, and the reduced g-vectors data reflects this. The $\mathrm{Cu}$ acetate in ZSM-5 is significantly different from data for all of the other complexes. The single resonance at a g-value of 2.1 suggest that the environment of this sample is quite different from these model catalysts, and different from that of isolated copper atoms in zeolites, reported in the literature.

It is important to know that the catalytic properties of the copper bipyridyl dimer on silica and zeolite $\mathrm{Y}$ are similar and much different from the other catalysts. The supported copper bipyridyl dimer catalysts show very low, steady-state conversions of NO; whereas, the copper/ZSM-5 catalysts show higher, stable reactivities. These results suggest that the EPR data of the catalysts in the raw state may not be a good predictor of their performance in the working state. 


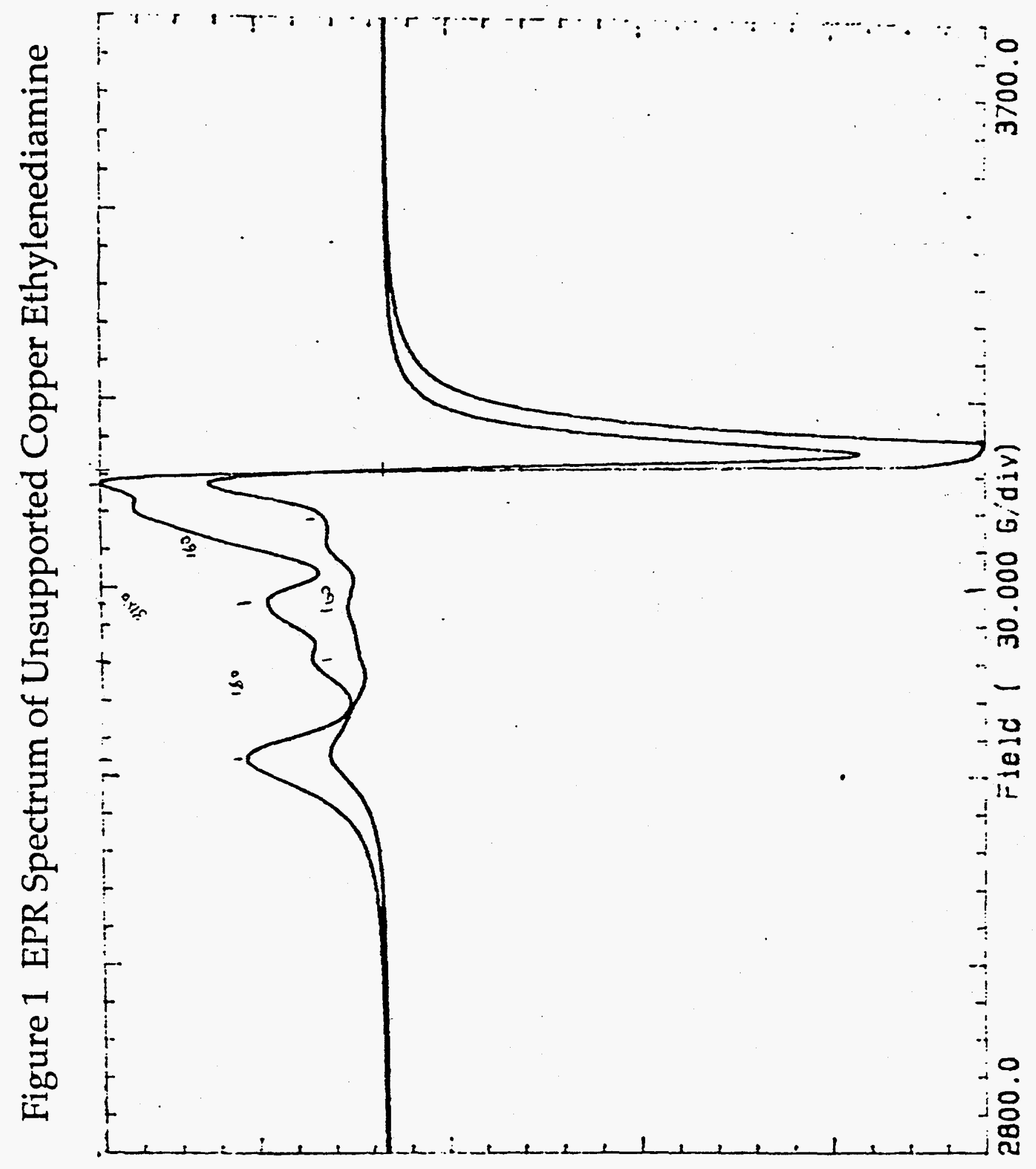


Figure 2 EPR Spectrum of Supported Copper Ethylenediamine

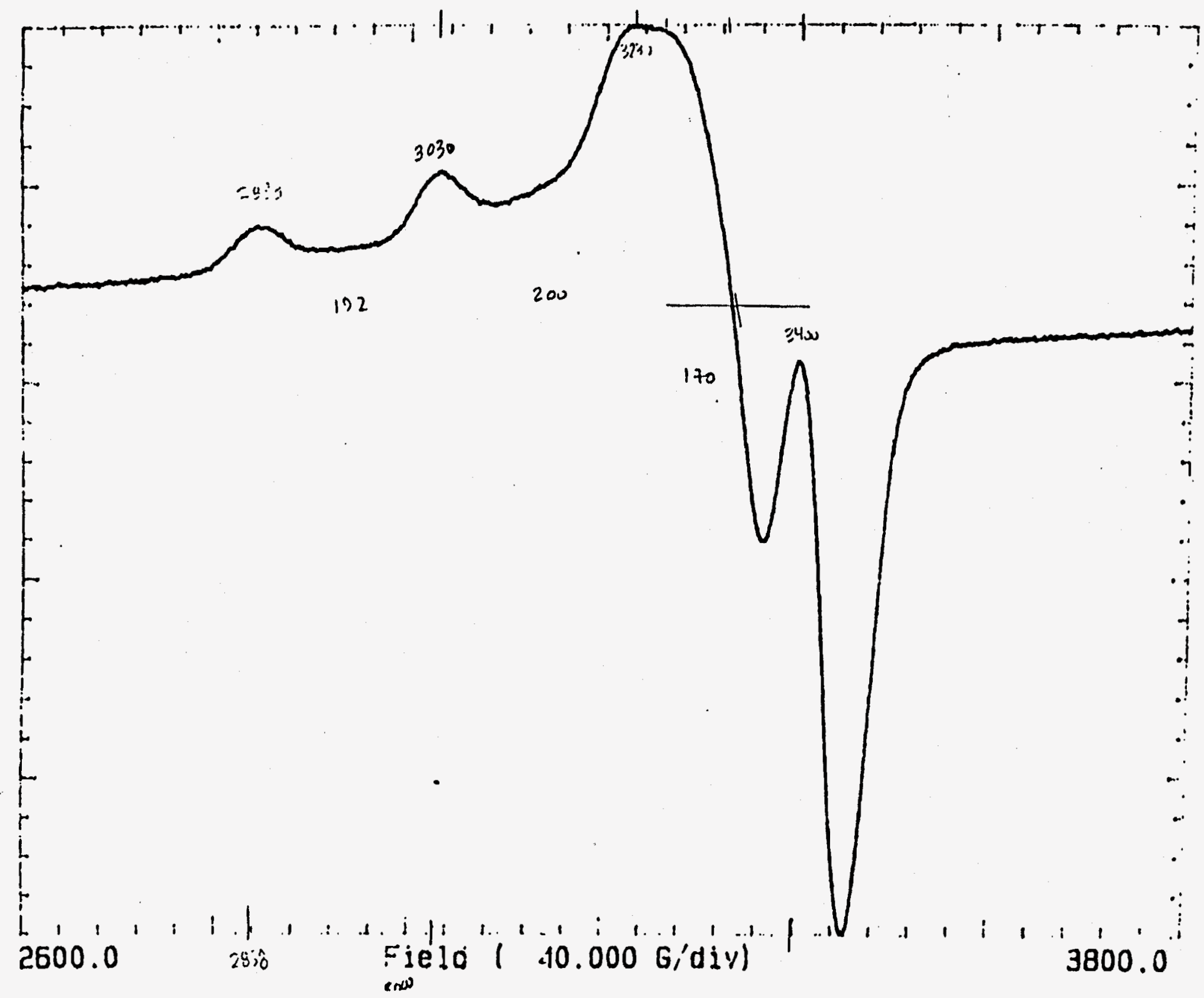




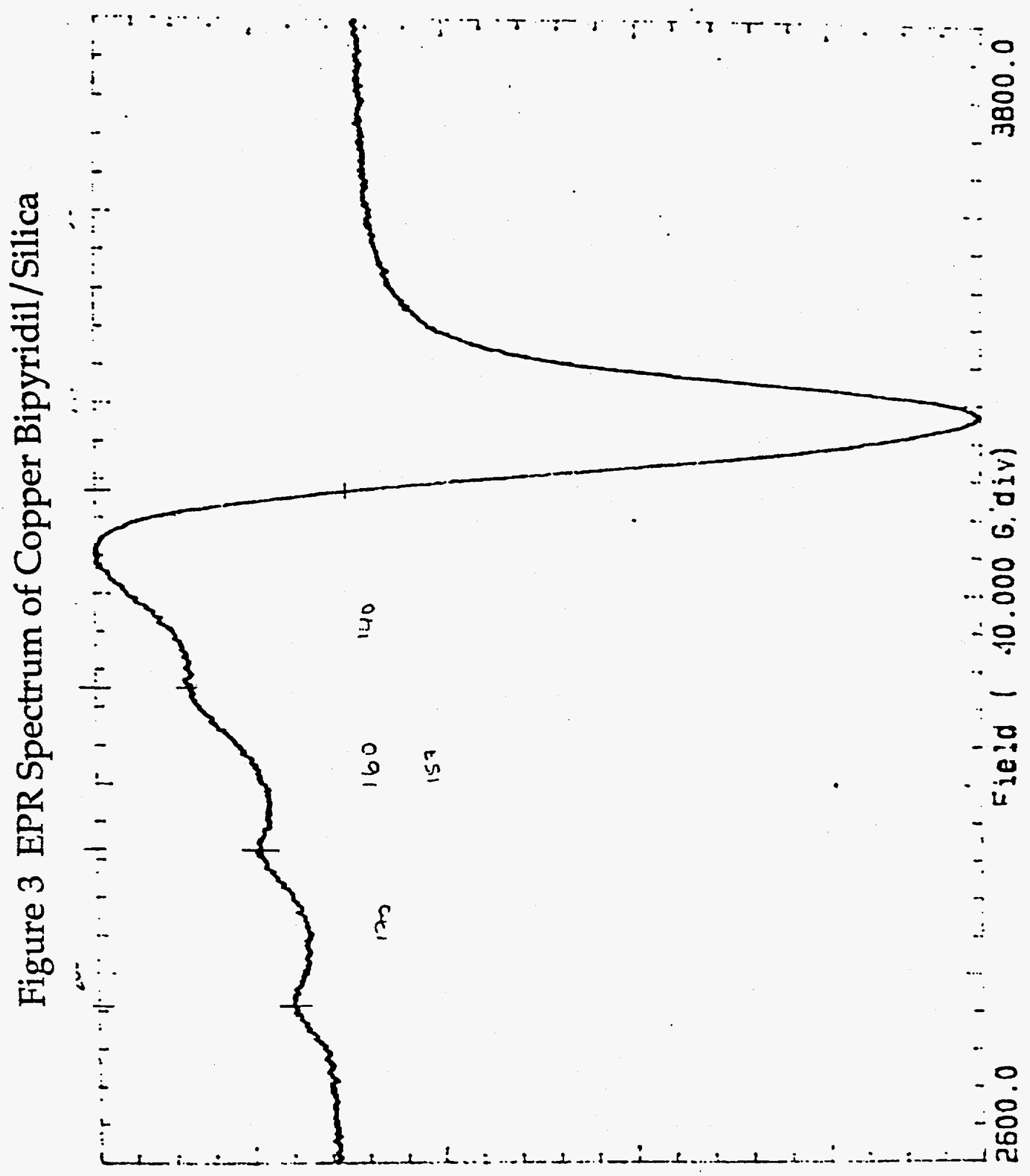




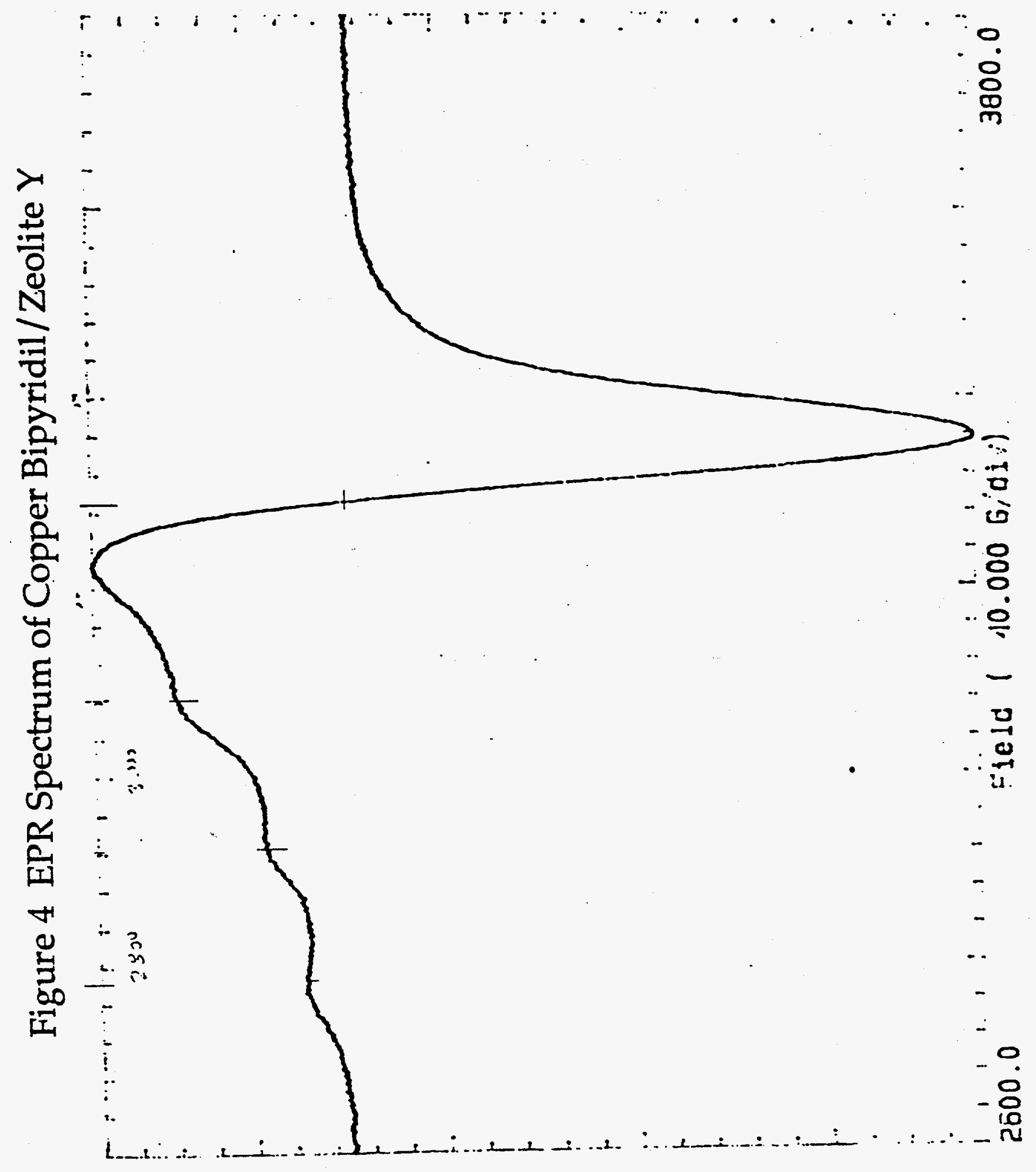




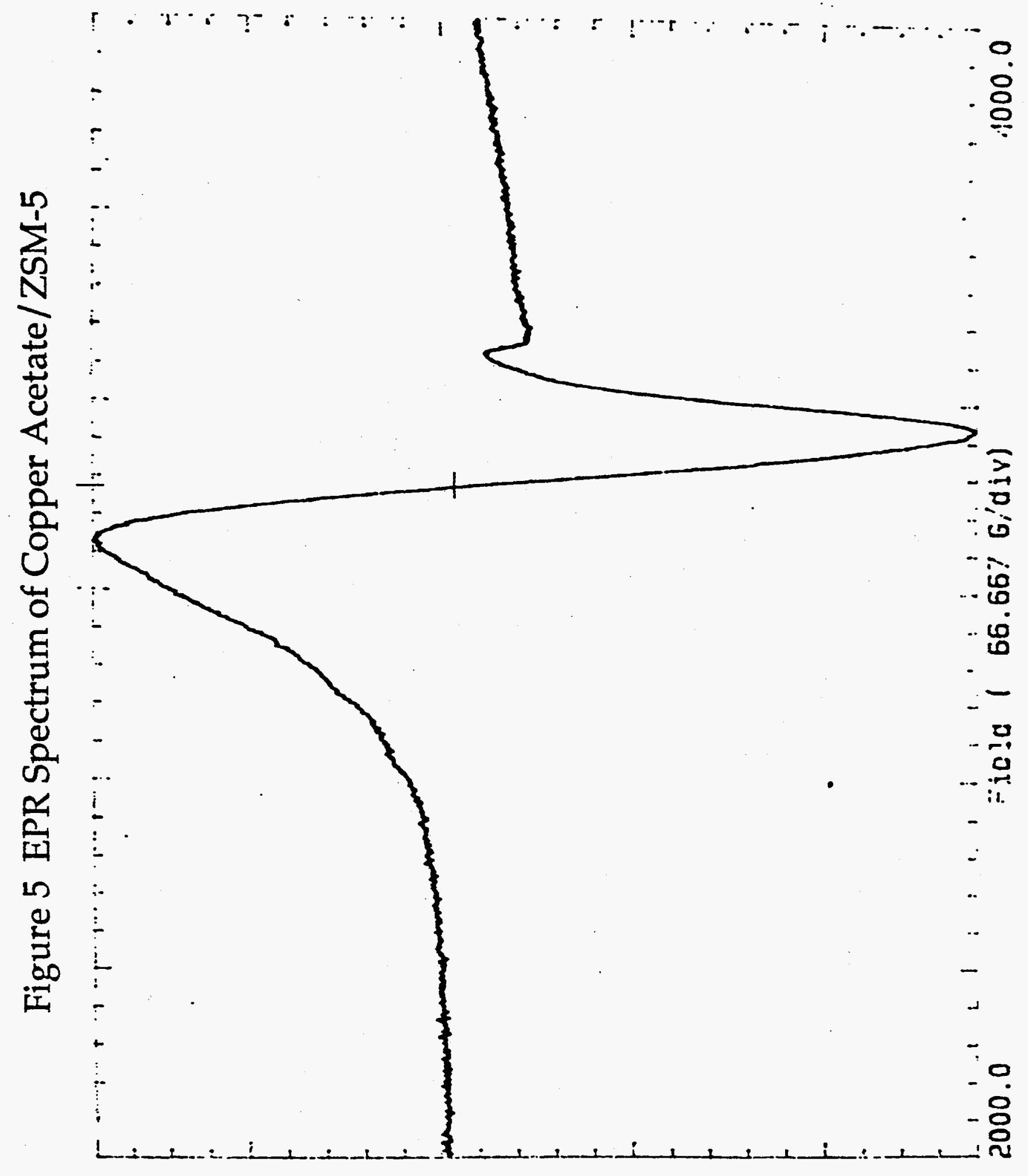

